\title{
ADDENDA PRAEFATIONIS SUPPLEMENTO I
}

Casu quodam factum est, ut absoluto demum opere codicum quorundam specimina a Torstrikio comparata mihi obvenirent, quae, ne quid desit, hic subiciam.

Corsuinianus 157 (C) ex Parisino 1972 (Pa) [vide Porph. Isag. CPa p. XIX] descriptus est. hic f. $118^{v}-209^{v}$ Ammonii librum Magentini expositionibus interruptum habet. auctoritate est nulla.

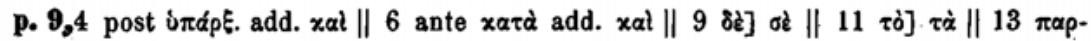

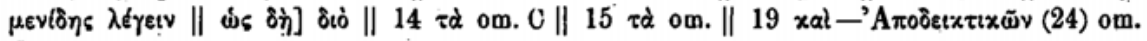

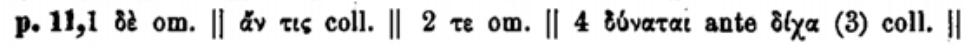

Oxon. Collegir Nori 234 [Catal. p. 85] chartaceus saeculo XVI ex- E

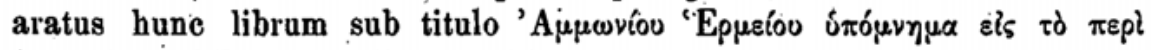

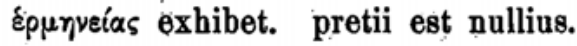
om. $\|$

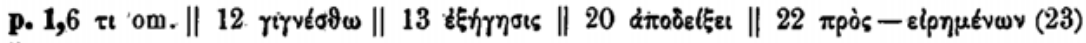

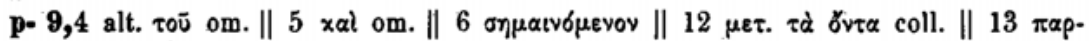

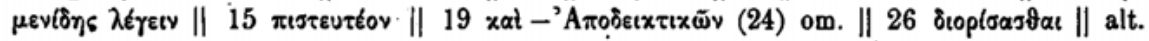

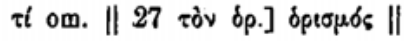

Eșcurialensis $\Phi$-III-10 [Miller p. 172] bombycinus saeculo XIII Fa vel XIV exaratus a f. $59^{\circ}$ Aristotelis librum De interpr. Ammonii com-

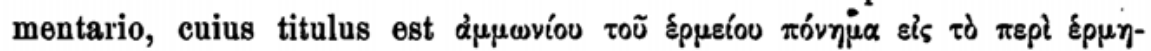
veías, ornatum exhibet. sed Aristotelis liber iam in verbis quae p. $19^{\text {b }} 31$ leguntur desinit, itemque Ammonii commentarius in fine mutilatus est. fide hic codex similis est codici $M$.

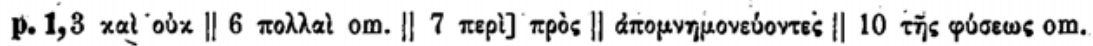

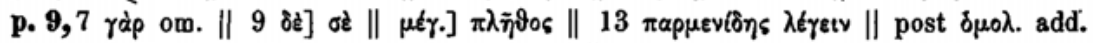

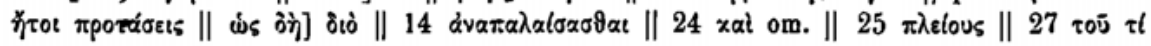

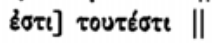

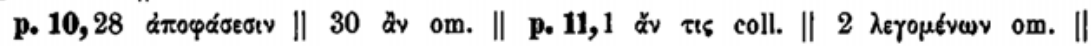

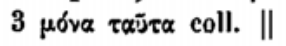


$P^{b}$ Parisinus 2088 [H. Omont II p. 192] bombycinus saeculo XIV scriptus inde a f. 39r Ammonii librum continet anteposito titulo $\alpha \mu \beta \omega-$

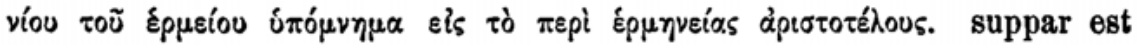
codici $\mathbf{E}$ atque etiam fide ille inferior.

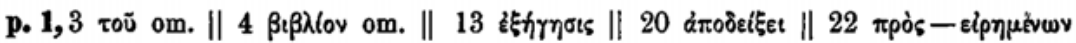
(23) om. \|

Ua Urbinas 58, quem Brandis neglexit, et aetate et fide videtur omnium esse infimus.

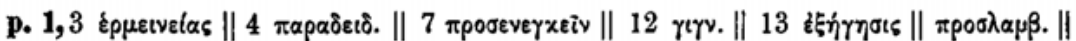

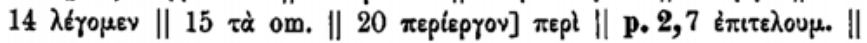

Ub Urbinas 57, quo Brandis p. 55 dicit Ammonii commentarium con-

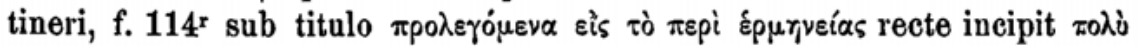

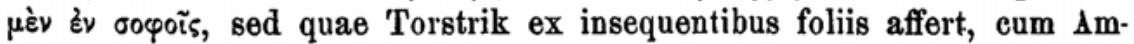

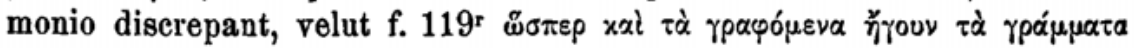

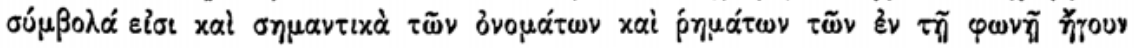

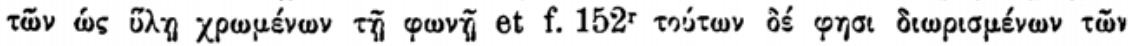

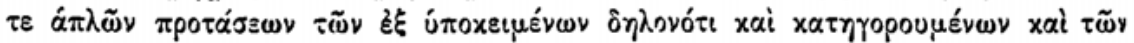

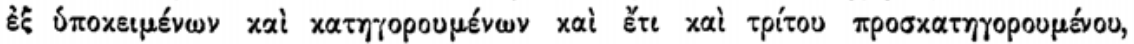

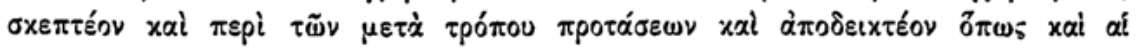

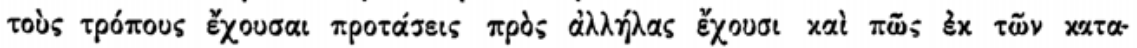

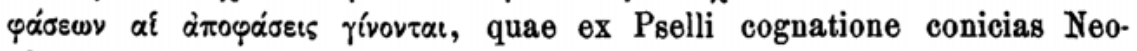
phyti esse.

$\mathrm{V}^{\mathrm{a}}$ Vaticanos 1018 [Brand. p. 52] chartaceus saeculo XV vel XVI scriptus f. $155^{\mathrm{r}}-160^{\mathrm{v}}$ Ammonii prolegomena habet titulo anteposito

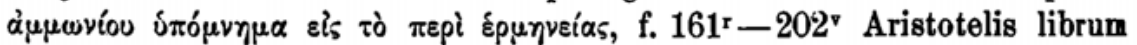
scholiis ex Ammonio petitis instructum. fide editioni Aldinae longe cedit.

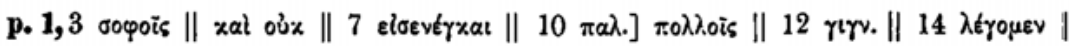

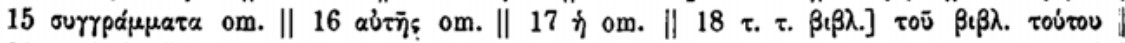

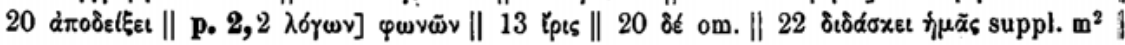

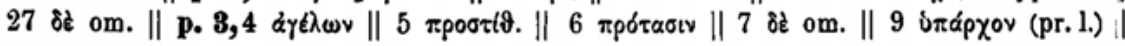

Denique tres codices Parisini Ammonii librum exhibentes nobis innotuerunt:

Po Parisinds 1974 [H. Omont II p. 173] chart. saec. XV f. 94-143.

$P^{d} \quad$ Parisinus 1898 [H. Omont II p. 160] chart. saec. XVI f. 1-80.

Pe Parisinos gr. suppl. 141 [H. Omont III p. 222] chart. saec. XVI f. $37-91$. 


\section{AMMONIUS \\ IN ARISTOTELIS \\ D E I N T E R P R E T A T I O N E COMMENTA R I U S}

